\title{
Idiopathic acquired sideroblastic anaemia transforming to acute myelosclerosis
}

\author{
AC BESTED,${ }^{*}$ G CHENG,$\dagger$ PH PINKERTON,${ }^{*}$ O KASSIM, $\ddagger$ JS SENN $\dagger$ \\ From the Departments of ${ }^{*}$ Laboratory Hematology, $†$ Medicine, and $\ddagger$ Pathology, Sunnybrook Medical \\ Centre, Toronto, Ontario
}

SUMMARY A case of idiopathic acquired sideroblastic anaemia transforming to acute myelofibrosis is reported. The appearance of atypical megakaryocytic proliferation in idiopathic acquired sideroblastic anaemia may presage the development of an acute myelofibrotic phase of this usually chronic disease.

Idiopathic acquired sideroblastic anaemia is a disorder of haematopoietic stem cell differentiation and proliferation, probably representing the emergence of an abnormal haemopoietic clone.' While patients with this disease, usually elderly, often die of unrelated causes, this disease often undergoes transformation to acute leukaemia. ${ }^{2-7}$ Transformation to acute myelofibrosis, however, is rare ${ }^{8-10}$

We report a patient with idiopathic acquired sideroblastic anaemia who developed acute myelofibrosis. " In addition to the characteristic ring sideroblasts and erythroid hyperplasia, this patient's bone marrow showed atypical megakaryocytic proliferation before progression to acute myelofibrosis.

\section{Case report}

A 68 year old white man presented in April 1981 with fatigue and a seven year history of insulin dependent diabetes mellitus. There was no history of other chronic disease, excessive use of alcohol, or exposure to lead or relevant drugs. Physical examination was unremarkable, without splenomegaly or lymphadenopathy. Peripheral blood findings were as follows: haemoglobin concentration $10.8 \mathrm{~g} / \mathrm{dl}$, white cell count $6.2 \times 10^{9} / 1$ (normal differential), and platelet count $135 \times 10^{9} / 1$. The blood film showed both hypochromic microcytic and normochromic normocytic red cells, with a few oval macrocytes. Serum iron concentration was $32 \mu \mathrm{mol} / \mathrm{l}$ (normal range $13-30 \mu \mathrm{mol} / \mathrm{l})$, total iron binding capacity was $38 \mu \mathrm{mol} / \mathrm{l}$ (normal range $50-70 \mu \mathrm{mol} / \mathrm{l}$ ), with a saturation of $0 \cdot 84$ (normal range $0 \cdot 2-0 \cdot 5$ ). Serum vitamin $B_{12}$, red cell folate, and serum ferritin concentrations were within normal limits. The bone marrow

Accepted for publication 6 June 1984 was hypercellular with hyperplastic erythropoiesis, mild dysplastic changes, and numerous ring sideroblasts (Fig. 1). Granulopoiesis was unremarkable. Megakaryocytes were clearly increased in number with more than normal variation in size, nuclear form, ploidy, and nuclear to cytoplasmic ratio. Idiopathic acquired sideroblastic anaemia was diagnosed.

The patient was given blood transfusion, but otherwise his clinical and laboratory findings did not change appreciably until October 1982 , when neutropenia, increasing thrombocytopenia, and palpable splenomegaly were found. By January 1983 , thrombocytopenia was severe (platelet count $20 \times 10^{9} / 1$ ) and the blood film became leukoerythroblastic with the presence of myelocytes $\left(0.4 \times 10^{9} / \mathrm{l}\right)$ and occasional blast forms (haemoglobin concentration 7.7 $\mathrm{g} / \mathrm{dl}$, white cell count $\left.2.6 \times 10^{9} / \mathrm{l}\right)$. Attempts at bone marrow aspiration yielded a "dry tap." Bone marrow biopsy showed a hypercellular marrow with, as before, atypical megakaryocytic proliferation now accompanied by increased reticulin and collagen fibres (Fig. 2). Erythroid and granulopoietic elements were present with evidence of differentiation. Acute myelofibrosis was diagnosed.

In March 1983 he became jaundiced. Liver function tests suggested hepatitis, but radioimmunoassay for hepatitis B surface antigen was negative. A provisional diagnosis of non- $A$, non- $B$ hepatitis was suggested. In early April he developed bronchopneumonia. Sputum cytology showed malignant cells. A few days later he fell and suffered epidural and intracranial haematomas, and he died on 7 April.

Permission was obtained for a limited necropsy, which revealed the following: splenomegaly $(0.5 \mathrm{~kg})$, with extramedullary haematopoiesis; 


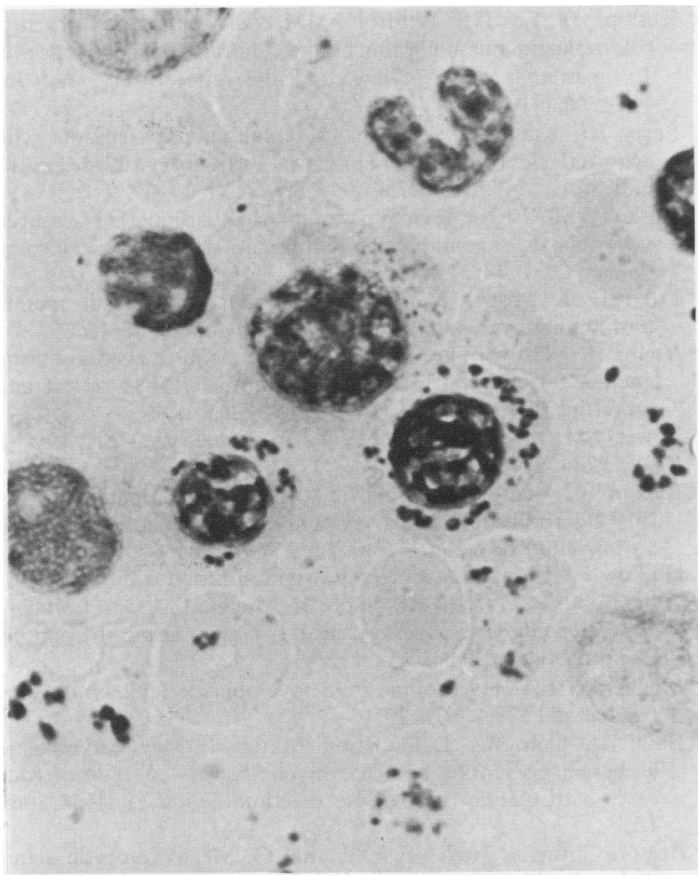

Fig 1 Bone marrow film showing erythrocytes and erythroblasts containing Prussian blue positive granules (ring sideroblasts). Prussian blue reaction counterstained with $1 \%$ neutral red. Original magnification $\times 1800$.

myelofibrosis of the bone marrow with atypical megakaryocytic hyperplasia and increased reticulin fibres; haemosiderosis of the liver without evidence of parenchymal inflammation; and KimmelstielWilson diabetic glomerulonephropathy of the kidney. Adequate examination of the lungs and any examination of the brain and meninges were precluded by the limited nature of the necropsy.

\section{Discussion}

Idiopathic acquired sideroblastic anaemia usually occurs in older patients and is characterised by a chronic course. While death often occurs owing to intercurrent disease, it is not uncommon for the condition to undergo transformation to acute leukaemia. ${ }^{3-7}$ While acute lymphoblastic leukaemia has been reported, ${ }^{12}$ acute myeloid leukaemia is the usual form. The cause of the predisposition is unclear, but evidence indicates that both acute myeloid leukaemia and idiopathic acquired sideroblastic anaemia may be clonal disorders originating in pluripotent stem cells. ${ }^{1}{ }^{13}{ }^{14}$ While erythroid,

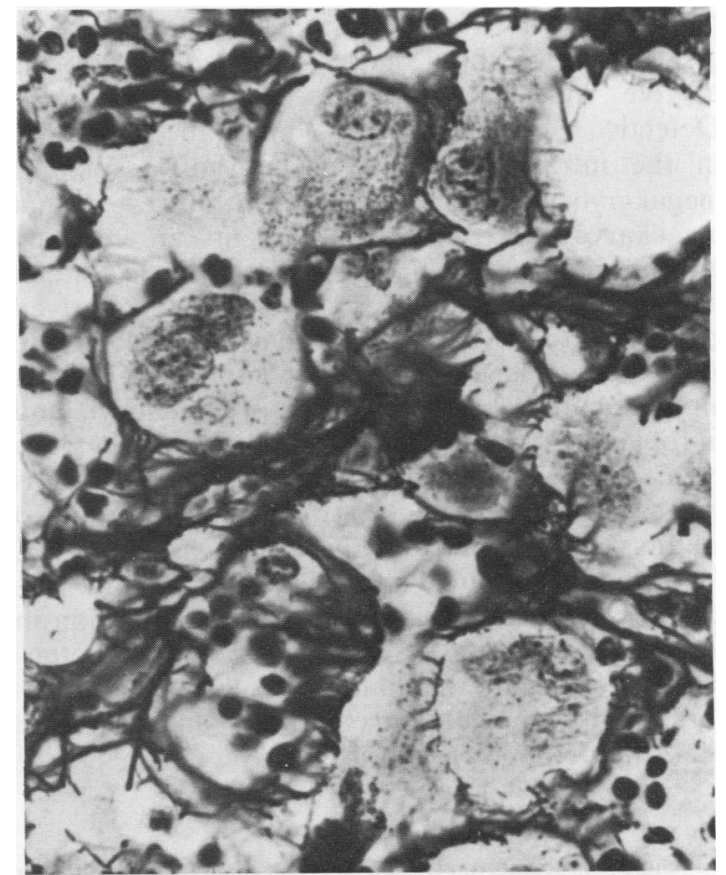

Fig 2 Bone marrow biopsy sample showing atypical megakaryocytic proliferation accompanied by increased deposition of reticulin fibres. Silver impregnation, counterstained with iron haematoxylin. Original magnification $\times 775$.

granulocytic, monocytic, and platelet lineages derive from a common pluripotent stem cell, marrow fibroblasts are probably of separate origin. ${ }^{13}$

It is rare for idiopathic acquired sideroblastic anaemia to progress to acute or malignant myelofibrosis. Lewis and Szur first identified malignant myelofibrosis as a separate entity in $1963 . .^{11}$ Yeung and Trowbridge ${ }^{10}$ described the first example of idiopathic acquired sideroblastic anaemia transforming to acute myelofibrosis in 1977. A further case was identified by Butler $e^{t} a^{8}$ which showed atypical megakaryocytic proliferation, and Lukowicz et $a l^{9}$ reported two patients with idiopathic acquired sideroblastic anaemia who had thrombocytosis associated with myelofibrosis.

In five cases of de novo acute myelofibrosis blast cells in the peripheral blood were characterised as being of megakaryocytic origin using the platelet peroxidase reaction. ${ }^{1516}$ Bain $e t$ al $^{15}$ postulated that acute myelofibrosis is secondary to the megakaryocytic proliferation. In most cases of idiopathic acquired sideroblastic anaemia transforming to acute myelofibrosis there has been evidence of 
megakaryocytic hyperplasia. Platelet derived growth factor has been suggested as having a role in the pathogenesis of myelofibrosis. Defective megakaryoctic maturation results in the intramedullary destruction of developing megakaryocytes, and it has been suggested that megakaryocytic cytoplasmic contents are released into the marrow, including megakaryocytic platelet derived growth factor and factor $4 .^{5}$ Platelet derived growth factor stimulates fibroblasts to proliferate and secrete collagen. Factor 4, contained in platelet alpha granules, causes inhibition of granulocyte and fibroblast collagenase, which normally degrades bone marrow collagen and reticulin fibres. ${ }^{17}$ It is suggested that as a result of the action of these two factors, collagen and reticulin fibres are increased, resulting in acute myelofibrosis. ${ }^{17}$

The presence of megakaryocytic proliferation in sideroblastic anaemia may have prognostic potential, indicating the likelihood of subsequent transformation into acute myelofibrosis and therefore predicting a poor prognosis.

\section{References}

' Prchal J, Throckmorton D, Carroll AJ. A common progenitor for human lymphoid and myeloid cells. Nature 1978;274:590-1.

${ }^{2}$ Catovsky D, Shaw MT, Hoffbrand AV, et al. Sideroblastic anaemia and its association with leukaemia and myelomatosis: a report of five cases. Br J Haematol 1971;20:385-93.

${ }^{3}$ Cheng DS, Kushner JP, Wintrobe MM. Idiopathic refractory sideroblastic anemia: incidence and risk factors for leukemic transformation. Cancer 1979;44:724-31.

${ }^{4}$ Dameshek W. Sideroblastic anaemia, is this a malignancy? Br J Haematol 1965; 11:52-8.

${ }^{5}$ Dameshek W. The Di Gugliemo syndrome revisited. Blood 1969;34:567-72.
' Kushner JP, Lee GR, Wintrobe MM, et al. Idiopathic refractory sideroblastic anemia: Clinical and laboratory investigation of 17 patients and review of the literature. Medicine 1971;50:139-59.

' Lewy RI, Kansu E, Gabuzda T. Leukemia in patients with acquired sideroblastic anemia: an evaluation of prognostic indicators. Am J Hematol 1974;6:323-31.

${ }^{8}$ Butler WM, Taylor HG, Viswanathan U. Idiopathic acquired sideroblastic anemia terminating in acute myelofibrosis. Cancer 1982;49:2497-9.

${ }^{9}$ Lukowicz D, Myers T, Grasso J, Albala M. Sideroblastic anemia terminating in myelofibrosis. Am J Hematol 1982; 13:253-7.

${ }^{10}$ Yeung K, Trowbridge AA. Idiopathic acquired sideroblastic anemia terminating in acute myelofibrosis. Case report and literature review. Cancer 1977;39:359-65.

"Lewis SM, Szur L. Malignant myelosclerosis. Br Med J 1963;ii:472-7.

${ }_{12}$ Barton JC. Acute lymphoblastic leukemia in idiopathic refractory sideroblastic anemia: evidence for a common lymphoid and myeloid progenitor cell. Am J Hematol 1980;9:109-15.

${ }^{13}$ Fialkow PJ. Clonal and stem cell origin of blood cell neoplasms. In: Lobue J, Gordon AS, Silber R, Muggia FM, eds. Contemporary hematology/oncology. Vol 1. New York and London: Plenum Medical Book Co, 1980:1.

${ }^{14}$ McCulloch EA. Haemopoiesis in myeloblastic leukaemia. Clin Haematol 1979;8:501-23.

is Bain BJ, Catovsky D, O'Brien M, et al. Megakaryoblastic leukemia presenting as acute myelofibrosis - a study of four cases with platelet peroxidase reaction. Blood 1981;58:20613.

${ }^{16}$ Breton-Gorius J, Reyes F, Duhamel G. Megakaryocytic acute leukemia: identification by the ultrastructural demonstration of platelet peroxidase. Blood 1978;51:45-60.

${ }^{17}$ Castro-Malaspina H, Moore MA. Pathophysiological mechanisms operating in the development of myelofibrosis: role of megakaryocytes. Nouv Rev Fr Hematol 1982;24:221-6.

Requests for reprints to: Dr PH Pinkerton, Department of Laboratory Hematology, Sunnybrook Medical Centre, 2075 Bayview Avenue, Toronto, Ontario, Canada M4N 3M5. 